\title{
Study on Application of Flipped Classroom Theory in College English Teaching
}

\author{
Geng Bing \\ Jinan University, College of Foreign Studies, Guangzhou, 510632
}

Key words: flipped classroom, college English teaching, independent study, education information

\begin{abstract}
Under the tide of our domestic education informationization reform, the flipped classroom originating from American education circle takes the constructivism theory as the guidance, and depends on the modern information technology. As an innovative teaching mode, it has aroused great concern and favor in our domestic education circle with its unique advantages. This paper takes the education information reform as the guidance, focuses on the origin and definition analysis of the flipped classrooms, starts from the current status of the college English teaching, elaborates the feasibility analysis and advantages of the classrooms to guide the college English teaching, puts forward related countermeasures and suggestions, provides classroom practice cases, so as to provide reference for our domestic colleges to implement the flipped classroom practice of the college English.

At present, originating from America, the flipped classroom as a new teaching idea and method that overturns the traditional teaching method has become a hot reform topic among the global education circle. Although the flipped classroom has already been promoted and implemented widely in America, and it has been highly praised and approved by American students and teachers, our domestic research and application about the flipped classroom is still in the beginning stage. Nowadays, the rapid development of our domestic information technology, promotion and application of the network technology and the effective implementation of the planning of the Ministry of Education provides wide platforms and good opportunities for the propaganda and application of the flipped classroom. In other words, the innovative teaching mode constructed by the flipped classroom is the product of the education informationization. It also can be regarded as the "damaging innovation" for the traditional teaching mode. As an international innovative teaching mode, the flipped classroom has unique advantage that the traditional teaching cannot achieve. To introduce the flipped classroom and apply it in our domestic college English teaching practice can effectively break through the dilemma of the current college English teaching development, which provides convenience for the students to study English. On essence, it is necessary to realize the deep reform of the college English teaching, and improve our domestic college English proficiency and students' comprehensive English application ability from listening, speaking, reading, writing, and translating.
\end{abstract}

\section{Definition and development of flipped classroom}

Most domestic and foreign researchers define the flipped classroom from the angle of the practice process and the learning essence process. The flipped classroom is also named as inverted classroom or inverted classroom. FCM is for shot. It refers that the teacher integrates the important points, difficult points with some new knowledge based on the taught content, and create related teaching videos; the students utilizes the after-class time to watch the teaching videos and learn the new courses on their own, to realize the knowledge transmission; afterwards, the students should complete the online testing according the teaching video, absorb and digest the new knowledge, and then participate in the interaction, communication, cooperation, sharing and discussion with the teachers and classmates by putting forward some doubts from the study, realize the complete comprehension and mastering of the new knowledge, and then complete the study.

Feasibility of the flipped classroom guiding the practice of the college English teaching Analysis 
(1) Dilemma of college English teaching

At present, compared with the junior-senior high school English, although the college English teaching gets rid of the constraint from the academic pressure, some local universities still regards the following point as the main teaching target: the students from non-English major pass CET-4, CET-6, TOEFL, IELTS, and postgraduate English. Such target goes through the exam-oriented education, which should be urgently innovated. English is regarded as a study of language culture. It is necessary to pay attention to the cultivation of the English communication skills, such as listening, speaking, etc. However, the improvement of the listening and speaking skills are established based on the premise that the students already have good English vocabulary, grammar, reading comprehension, writing and other basic knowledge, and proficiently master the skills. All of them should be completed under the good language environment. As the college English teaching tends to be restricted by the limited teaching time, fixed teaching places and limited teaching content, it is difficult to establish good and perfect English language environment. Therefore, it is also difficult to realize the training cultivation and comprehensive improvement of the students' listening, speaking, reading, writing, translating from the non-English major. The teachers should teach the knowledge from the books to the students in 45 minutes in class. The students are busy with taking records and listening to the teachers, so that they have few chances to attend the oral English training. Even if they have the chance, they will be afraid to speak out due to the nerve, fear, and timidity, so the teachers cannot provide relating guidance regarding correcting the pronunciation, listening and speaking, etc. Some English classrooms even have inflexible teaching content. The classroom design is boring, and the teaching mode is rigid [6]. In the English class, the students can learn but cannot put them into practice. Therefore, after long time, they will be tired of the English classes and lose the interest, which seriously affects the college English teaching effect.

(2) The advantages of the flipped classroom guiding the college English teaching practice

1. The flipped classroom adopts the new teaching mode "teaching after learning", which is favorable for cultivating students' independent study capability

According to Eric Mazur's theory, in general, the learning process mainly includes the knowledge transmission and knowledge internalization. The traditional teaching mode refers that the teachers transmit the knowledge in the classroom, and the students absorb the knowledge through completing the homework provided by the teachers after class, and once the students encounter problems during the knowledge internalization, the teachers cannot provide prompt help if they are not beside the students, which will affect the knowledge internalization effect. However, the essence of the implementation process of the flipped classroom is to reverse the "knowledge transmission" and "knowledge internalization" of the traditional teaching mode. The knowledge transmission process is transferred from the classroom to the post-class or family. The knowledge internalization process is transferred from the post-class or family to the classroom, and it realizes the complete reversing of the study process from the time and space, which is the new teaching mode of "teaching after learning" [7]. In addition, the teachers participate in the whole process of the students' knowledge internalization, which is favorable for effectively solving the students' difficulty. During the discussion and cooperation with the classmates, the students can absorb, consolidate and put the knowledge into practice, so as to give full play to the important study link "knowledge internalization", and then enables the teaching effect and learning effect to achieve qualitative leap. It is just the greatest advantage of the flipped classroom compared with the traditional classroom. Under the teaching mode of the flipped classroom, the college English teachers should firstly compact the important points of the teaching content and make a micro-video with 15 to 20 minutes.

The teachers do not show up in the videos, and only the explanation and interpretation are clearly mentioned, which prevents the students from distraction due to teachers' different dressing when watching videos. The teachers can integrate the animation, story interpretation, interesting questions and other elements into the production of the micro-video, so as to enable the students to get rid of the boring books and not being constrained by the rigid teaching content, and teach others through lively activities, which can arouse the students' great interest in studying the college 
English. The short and refined video eliminates the disadvantage that the traditional classroom requires 45 minutes to teach lessons and easily leads to students' distraction. The students focus on watching the teaching video after class or at home, and complete the online practicing for self-inspection. Meanwhile, they can replay, stop or repeat playing according their knowledge absorption capability, which is the process similar to the teachers' knowledge transmission in the traditional classroom, and overcomes the single direction of the knowledge transmission of the traditional classroom, and saves the time of knowledge transmission.

\section{The flipped classroom can effectively realize the classroom function, which is favorable for promoting the core flipping and promotion of the student and teacher role}

The flipped classroom adopts the integration mode of the online study and differential guidance, which helps the students absorb and internalize the knowledge to the greatest extent, and gives full play to the students' subjective role during the study, and effectively realizes the students' individualization and differentiation development. In this way, the classroom function can be effectively promoted during the process. It also remedies the disadvantage from the traditional teaching mode, and realizes the value appeal of the high-efficiency classroom.

It is worth of mentioning that, the flipped classroom is not the pronoun of "video teaching". In the classroom, it takes the interactive communication between the teachers and students as the "knowledge internalization" process of the external manifestation pattern, which is the core and key point of the flipped classroom [8]. Superficially, the flipped classroom seems to replacing the teachers with the video teaching. The function of the teachers is weakened. However, after the essence analysis, the roles of the teachers and students are changed during the implementation of the flipped classroom. It enables the teachers to change from the original "Saint on the platform" to the "surrounding guider" through flipping; enables the students to relieve from the original rigid teaching, and the students become "tutors" during the students' knowledge internalization, which strengthens the function of the teacher. Restricted by some objective and subjective conditions, the cultivation mechanism of our current college English teaching is still not perfect for the listening and speaking ability of the students from non-English major. However, the introduction of the flipped classroom can ensure that the teachers can communicate with the students in English, answer their difficulties, help them complete the knowledge internalization, and help them correct the pronunciation and expression under the premise of realizing the knowledge transmission of the books. Besides, it ensures the students can realize good language output under the premise of completing much language input, which is helpful for establishing students' confidence in independent English study and realize self-satisfaction and achievement sense.

\section{The flipped classroom creates multiple interactive communication mechanism, which is favorable for cultivating the relationship between the students and teachers}

In the traditional classroom teaching mode, as the main operator of the knowledge transmission, the teacher has the absolute right of speech in the classroom all along. The teaching status of "centered on teachers" enables the teachers to lead the absolute dominant role in the originally fair relationship. The students are in the subordinating status, which greatly restricts the students' innovation, brave, dispute ideology and thinking mode. By comparison, the classroom activity from the flipped classroom is changed from the unidirectional teaching of the teachers to bilateral communication. It creates multiple interaction mechanism between the teachers and students, and forms multi-dimensional communication mechanism, which increases the communication between the teachers and students, and which is favorable for the teachers to help them improve their knowledge internalization, and effectively cultivate their creative thought, disperse thought, logical thought, self-independent exploration capability, debating capability, communication, problem solving and collaboration and other comprehensive quality, and it can enhance the learning effect.

In addition, such teaching mode eliminates the student and teacher's hierarchy concept, speeds up the equalization between the classmate and students. It is favorable for reshaping the original 
equal relationship. During the communication, the students achieve good internal emotion experience. The teachers do not consider "students' right is supreme”. However, it is involved in the guider of the guider from the students' study, and friends from the life. Such relationship can become the spiritual motivation for the students during their study to overcome the setbacks. Besides, it can help the classroom solve this issue. The students will achieve mental and spiritual support and encouragement when facing the difficulties, which is favorable for cultivating students' pressure resistance, resistance against frustration and exploration subject, and then forms the best learning status of the positive cycle on the cycle (both teaching and tradition.)

\section{The specific operation of the flipped classroom to guide the college English teaching practice}

(1) Clarify the role and positioning of the teacher

In the flipped classroom teaching mode, the college English teacher should complete the change from "teacher-centered" to "student-centered" during the whole process of the college English. The teachers should firstly adjust the psychology, change the concept, and approve the new student-teacher relationship with equal status on concept, eliminate the hierarchy concept, and relieve from the absolute right of speech. They are no longer the authoritative knowledge initiator; instead, they are the guiders of assisting the students to study independently, clearing up the confusion and doubts.

As the guider, the teacher should understand the potential and advantage of each student, master their study progress difference and understanding degree difference, and master how to provide different "one-to-one" coaching for the students, effectively solve each student's difficulty and problem in the limited class time, accelerate their individual development, and abandon the original stereotyped common teaching [9]. These changes put forward great challenge to the teachers. The teachers are required to improve their professional work and comprehensive excellent guidance capability (including resource integration capability, judgment capability, professional quality, professional work, communication, collaboration, etc.)

(2) Improve the teachers and students' information technology quality

The popularization of the computer, the wide application of the network and the rapid development of the cloud technology in current society enable our life to enter into the big data era. The information technology (IT) has been permeated into the domains of the life. The education circle also cannot escape from this baptism. To successfully apply the flipped classroom in the college English teaching practice, both teachers and students should improve own IT quality and computer application skills. Firstly, the production of the teaching video should put forward higher requirements on the teachers' IT level. Only if the teacher mater certain IT and computer application skills, and integrate the important points of the courses into the short video and design checking practice meeting the courses, can the micro-video convey the knowledge without barriers, and the students' independent study schedule and knowledge mastering status be followed up. Besides, students can utilize the computer terminal, tablet PC or smart phone to effectively complete the pre-school independent study and pre-school practice (online self-inspection testing) based on certain computer application level, and find out the root causes of the difficulties. Therefore, the IT level should not become the barrier for the English teaching to carry out the new mode of the flipped classroom. The teacher and student should strengthen their own IT quality and computer application level, which is basis and premise of effectively conducting the interaction in the flipped classroom, and also the effective guarantee of the specific practice.

(3) Improve students' independent study capability

The effect of the students to independently learn the micro-video courses before class directly influences the implementation and effect of the knowledge internalization process in the flipped classroom. The flipped classroom shows that, the way that the teachers unidirectionally transmitting knowledge to the students is changed to students' watching micro-video and realize the knowledge reversing study, which is the complete change and beneficial supplement towards the knowledge transmission process. in this way, it puts forward higher requirements to the students' independent study capability and disciplinary. Before class, the student becomes the automatic adjuster of the 
learning step. Namely, according to the own study status, it selects study time and space, and masters the process and tone of the learning content and amount. In class, they highly participate in the communication with the teachers and classmates. During the discussion, they continue to explore and create new knowledge with certain width and breadth. The improvement of students' independent study capability and development of the individual study provide lifelong benefits to the students, which is the fundamental approach for actually promoting the effectiveness of the college English teaching, and the only choice for realizing the students' improvement from school education to the self-education.

\section{Conclusion}

As the new innovative teaching mode of the information era, the flipped classroom complies with the tide of the present informationization reform, and meets the tenet of Ten-year Development Plan of Education Informationization (2011-2020) issued by the Ministry of English. Namely, the development of the education informationization takes the education concept innovation as the guidance, and the superior education resource and informationization study environment construction as the basis, and the learning mode and education mode innovation as the core [10]. Aiming at the current status that our domestic college English teaching should urgently reform, the introduction and practice of the flipped classroom can remedy the defect of the college English teaching to some extent, accurately master the objective regularity of the development, stably break through the development bottleneck, give full play to the students' subjective initiative, and improve students' learning efficiency and effect, which designs a set of successful and feasible proposal for the reform and development of our domestic college English teaching, and also injects new vitality into our domestic education circle for realizing the education informationization reform.

\section{References}

[1] [10] The Ministry of Education. Ten-year Development Plan of Education Informationization, 2011-2020.

[2] Zhang Jinlei, Wang Yin, Zhang Baohui. Study on Teaching Mode of Flipped Classroom [J]. Distance Education Journal, 2012, (8): 46-51.

[3] Song Yanling, Meng Zhaopeng, Yan Yajuan. Study Flipped Classroom from Viewpoint of Cognitive Load - Analysis on Typical Mode of Flipped Classroom [J]. Distance Education Journal, 2014 (1): 105-112.

[4] Ma Mingshan, Qiao Dandan, Wang Xiangzheng. Khan Academy Course Assessment and Enlightenment in Public View [J]. China Educational Technology, 2014, (1): 93-98. 